\title{
The Design and Simulation of Electro-Hydraulic Velocity Control System
}

\author{
Fengtao Lin ${ }^{*}$ \\ Key Laboratory of Ministry of Education for Conveyance and Equipment, \\ East China Jiaotong University, Nanchang 330013, China \\ menggu_lin@163.com
}

\begin{abstract}
In this paper, the principle of electro-hydraulic proportional control system are introduced, electro-hydraulic velocity control system are designed and can realize volevity control with high accuracy. In the system, relative amplitude abundant degree and phasic abundant degree and corresponding frequency of passing of Body system is easily obtained under different open ring gain of $\mathrm{K}$, thus it is simple and accurate to choose reasonable parameters, and then can carry on smulation to system by Matlab/Simulink to examine the design results.
\end{abstract}

Keywords: Electro-hydraulic servo system, Matlab, Simulation.

\section{Introduction}

Velocity control system[1,2]is widely used in practical projects need for velocity control, such as turrets, radar, turntable, etc; and the projects need for straight line motion velocity control, such as lifting platform, mail-sorting machine automatically conveyor, machine tool feeding device, etc. velocity control system with electro-hydraulic servo controller is a control circuit that output velocity variation feeds back to the input side via the sensor.

In electro-hydraulic velocity control system[3,4] designing, the traditional approach is to identify the system composition and control mode based on the requirements, then to build the mathematical model and the system parameters, and adjust the open loop gain $\mathrm{K}$ of the system to ensure the system stability based on the bode diagram or nyquist diagram analysis of the open loop transfer function.

In this paper, open-loop transfer function of a system was described use matlab language, the amplitude margin, phase margin, and the corresponding crossover frequency of the relatively stable system can be calculated after evaluating the $\mathrm{K}$ value.

According to the critical condition of the system stability margin, the $\mathrm{K}$ value is adjusted and the new gain margin and phase margin were calculated repeatedly until at least one of the margins close to the critical condition steadily at the premise of all stability conditions are meet. and the parameters $\mathrm{k}$ value was decided. In this way, the open loop system amplitude and crossover frequency increased as much as possible, and also ensure the system stability. A rotating device velocity control system design of an equipment was presented as an example to illustrate the application of this method.

* Corresponding author. Tel.: 13970842969. 


\section{Methods and Applications}

A device rotator system parameters are defined as follows[5]: Load rotational inertia $J=0.4 \mathrm{~kg} \cdot \mathrm{m}$, rotational velocity range $n=35 \sim 200 \mathrm{r} / \mathrm{min}$, Working Pressure $p=8 \mathrm{MPa}$, Maximum load torque $M=50 \mathrm{~N} \cdot \mathrm{m}$, static gain of velocity Sensor is $20 \mathrm{~V} / 1000 \mathrm{r} \cdot \mathrm{min}^{-1}$, and performance index requirements are defined as follows: tracking precision is $\pm 1 \mathrm{r} / \mathrm{min}$, completing the tracking task accurately within $0.15 \mathrm{~s}$.

\subsection{Working Principle of the Contronl System}

As the control power is smaller, so valve- controlled electro-hydraulic system[6] is dominated directly by the servo valve. The working principle is shown by Fig. 1.

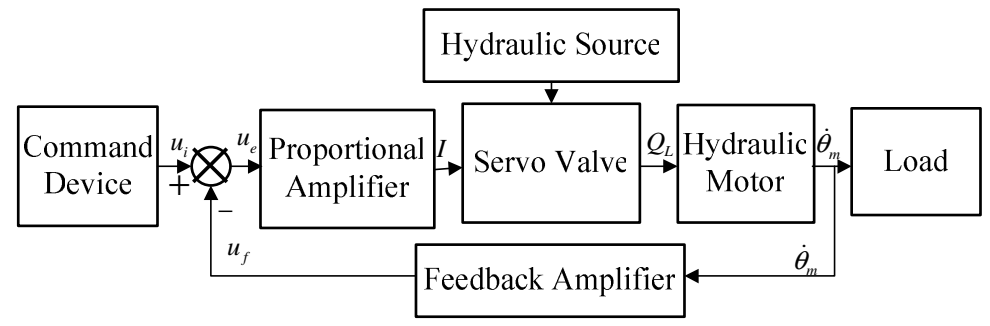

Fig. 1. Diagram of system working principle

Where, $u_{i}$ is velocity contronl singal; $u_{e}$ is deviations; $I$ is input current; $Q_{L}$ is servo valve flow; $\theta_{m}^{\prime}$ is output velocity; $u_{f}$ is feedback.

\subsection{Motor Discharge}

In this paper, maximum load value is two-thirds of supply oil pressure value and is found to be:

$$
P_{L}=\frac{2}{3} P=\frac{2}{3} \times 8 \times 10^{6}=5.3 \mathrm{MPa}
$$

motor discharge is found to be: $D_{m}=\frac{2 \pi M}{2 \pi P_{L}}=\frac{50}{5.3 \times 10^{6}}=9.434 \times 10^{-6} \mathrm{~m}^{3} / \mathrm{rad}$

The BM1210 type cycloid hydraulic motor was selected, and the discharge $D_{m}$ is: $163 \times 10^{-7} \mathrm{~m}^{3} / \mathrm{rad}$. 


\subsection{Servo Valve Specifications Determination}

The servo valve flow is found to be:

$$
Q_{L}=2 \pi D_{m} n_{\max }=2 \pi \times 163 \times 10^{-7} \times 200=20.4 \times 10^{-3} \mathrm{~m}^{3} / \mathrm{min},
$$

pressure drop is:

$$
p_{V}=p-p_{L}=80 \times 10^{5}-53 \times 10^{5}=27 \times 10^{5} \mathrm{~Pa}
$$

QDYI2C63 type servo valve can meet the parameters requirements, and it's rated no-load flows $Q_{V}$ is $1.05 \times 10^{-3} \mathrm{~m}^{3} / \mathrm{s}$, rated current $I_{V}$ is $0.03 \mathrm{~A}$, supply oil pressure is $137 \times 10^{5} \mathrm{~Pa}$.

\subsection{The Dynamic Characteristic Determination}

Control system diagram is shown as figure 2, where, $K_{a}$ is integral amplifier gain, $K_{V}$ is servo valve gain, $\xi_{V}$ is damping ratio of the servo vaulve, $\omega_{V}$ is natural frequency of servo valva; $D_{m}$ is the hydraulic motor displacement, $\omega_{h}$ is natural frequency of hydraulic motor, $\xi_{h}$ is the damping ratio of hydraulic motor.

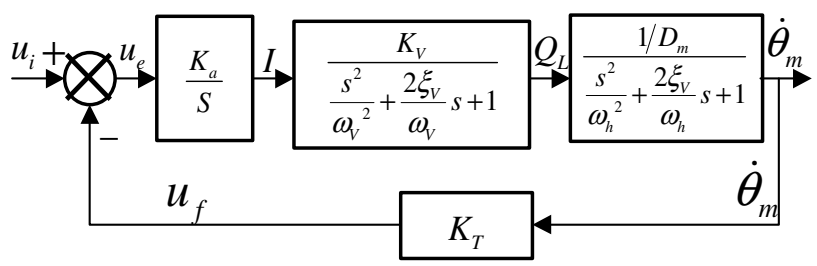

Fig. 2. Control system diagram

1) the transfer function of electro-hydraulic servo valve the servo valve gain is defined as follows:

$$
K_{V}=\frac{Q_{V}}{I_{V}}=\frac{1.05 \times 10^{-3}}{0.03}=3.5 \times 10^{-2} \mathrm{~m}^{3} / \mathrm{s} \cdot \mathrm{A}^{-1}
$$

Dynamic parameters of servo valve are decided in accordance with sample values, and natural frequency $\omega_{V}$ is $340 \mathrm{rad} / \mathrm{s}$, damping ratio $\xi_{V}$ is 0.70 , so the transfer function expression can be prescripted as follows:

$$
\frac{Q_{L}}{I}=\frac{3.5 \times 10^{-2}}{\frac{s^{2}}{340^{2}}+\frac{2 \times 0.7}{340} s+1}
$$


2) The transfer function of hydraulic motor

By calculation, the total volume of motor oil cavity and the volume between servo valve to the motor is $V_{t}=50 \times 10^{-6} \mathrm{~m}^{3}$, effective volume elasticity coefficients $\beta_{e}=7000 \times 10^{5} \mathrm{~Pa}$,So natural frequency expression of motor can be defined as follows:

$$
\omega_{h}=\sqrt{\frac{4 \beta_{e} D_{m}^{2}}{J V_{t}}}=193
$$

and damping ratio $\xi_{h}=0.2$, then the transfer function of hydraulic motor can be shown as follows:

$$
\frac{\theta_{m}^{\prime}}{Q_{L}}=\frac{\frac{1}{163 \times 10^{-7}}}{\frac{s^{2}}{193^{2}}+\frac{2 \times 0.2}{193} s+1}=\frac{0.62 \times 10^{5}}{\frac{s^{2}}{193^{2}}+\frac{2 \times 0.2}{193} s+1}
$$

3) Transfer function of velocity sensor determination

Static gain of velocity sensor is $20 \mathrm{~V} / \mathrm{r} \cdot \mathrm{min}^{-1}, K_{T}=0.02 \mathrm{~V} / \mathrm{r} \cdot \mathrm{min}^{-1}=0.19$ $\mathrm{V} \cdot \mathrm{s} / \mathrm{rad}$ transfer function of integral amplifier is defined as follows:

$$
\frac{I}{u_{e}}=\frac{K a}{S}
$$

\subsection{Integral Amplifier Gain Determination}

Transfer function of open loop system is defined as follows:

$$
\begin{gathered}
W(S)=\frac{K a \times 3.5 \times 10^{-2} \times 0.62 \times 10^{5} \times 0.19}{s\left(\frac{s^{2}}{340^{2}}+\frac{2 \times 0.7}{340} s+1\right)\left(\frac{s^{2}}{193^{2}}+\frac{2 \times 0.2}{193} s+1\right)} \\
K=K_{a} \times 3.5 \times 10^{-2} \times 0.62 \times 10^{5} \times 0.19=2170 K a
\end{gathered}
$$

Based on Bode diagram of the system, $G_{m}$ is the stable amplitude margin, $W c g$ is the crossover frequency of the corresponding phase; $p_{m}$ is phase margin, $W_{c p}$ is the crossover frequency of the corresponding amplitude.

For the control engineering practice, stability margin must be ensured, so the parameters of the system are prescribed as follows: $G_{m}>6 \mathrm{~dB}$, that is: $G_{m}>2 ; p_{m} \geq 30$, The system is single input-output system, the program was designed as follows: 


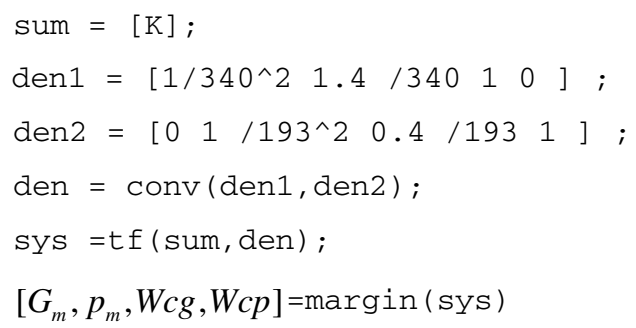

The results are shown as follows:

Table 1. Results of the program operation

\begin{tabular}{|c|c|c|c|c|}
\hline & 1 & 2 & 3 & 4 \\
\hline$K$ & 34 & 36 & 36.9 & 37 \\
\hline$G_{w}$ & 211733 & 210525 & 210025 & 119971 \\
\hline$p_{m}$ & 7713982 & 7615790 & 7612054 & 7611636 \\
\hline$W_{c g}$ & 16214235 & 16214235 & 16214235 & 16214235 \\
\hline$W_{c p}$ & 3510674 & 3712818 & 3812880 & 3814002 \\
\hline Explanation & $\begin{array}{l}\mathrm{Gm}>2, \mathrm{Pm} \text { is } \\
\text { great, System is } \\
\text { stable }\end{array}$ & $\begin{array}{l}\text { Gm>2,Pm and } \\
\text { Wcp are great, } \\
\text { System is stable }\end{array}$ & $\begin{array}{l}\mathrm{Gm}>2, \mathrm{Pm} \text { is great, } \\
\text { System is stable, } \\
\text { Gm is approach to } \\
\text { criticality }\end{array}$ & $\begin{array}{l}\text { Gm }<2 \text {, and } \\
\text { system } \\
\text { stability can't } \\
\text { be ensured }\end{array}$ \\
\hline
\end{tabular}

In this paper, $K=36.9$ based on the analysis of table 1 , and so there be:

$$
K a=\frac{36.9}{3.5 \times 10^{-2} \times 0.62 \times 10^{5} \times 0.19}=0.089479
$$

Transfer function of open loop system was shown as follows:

$$
W(S)=\frac{36.9}{s\left(\frac{s^{2}}{340^{2}}+\frac{2 \times 0.7}{340} s+1\right)\left(\frac{s^{2}}{193^{2}}+\frac{2 \times 0.2}{193} s+1\right)}
$$

\subsection{The Steady-State System Error}

The open loop system is 1 type system because the introduction of an integral part. The error of system response to velocity instruction is zero, which can fully meet the tracking accuracy requirements of $\pm 1 \mathrm{r} / \mathrm{min}$.

\subsection{System Simulation and Results}

System simulation diagram is shown by Fig. 3. and simulation results of system response to step signals is shown by Fig. 4 . 


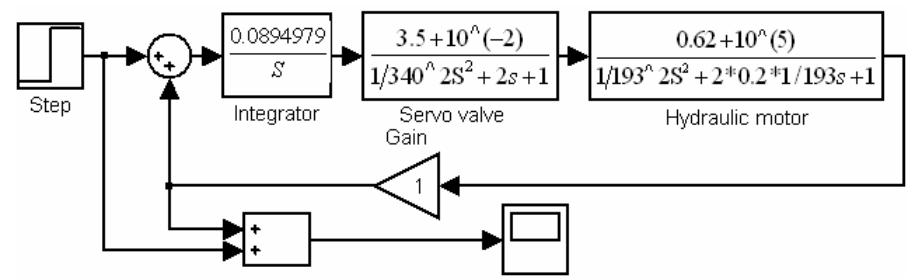

Fig. 3. System simulation diagram

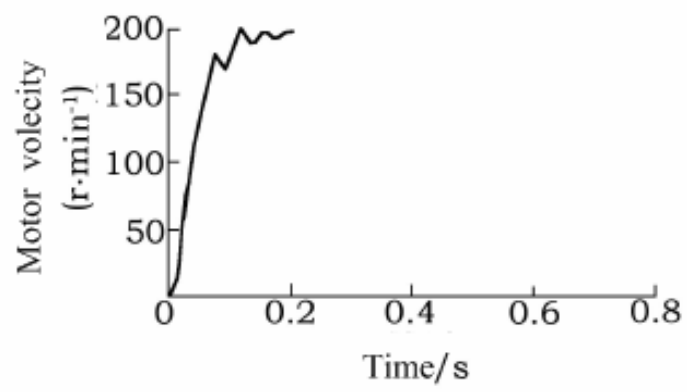

Fig. 4. Simulation results of system response to step signal

The simulation results show that the existing system is stable and non-overshoot, the increasing process was not monotonous, with a few small oscillations. the transition process within $0.11 \mathrm{~s}$, and quickly reach convergence. so the system can complete the tracking task accuratly within $0.5 \mathrm{~s}$, the volecity control system design is meet the requirements very well.

\section{Conclusion}

1) In the velocity control system designing, relatively stable amplitude margin, phase margin, the crossover frequency of the corresponding phase and reasonable system parameters can be easy to calculated accurately based on the simulation of open loop system use matlab language.

2) Simulation on the designed system using matlab/simulink can predict the results, verify correctness and provide a reference for designers. Availability of the simulation results depends on the correctness of the mathematical model, so rational model and parameters selection of the system are important.

Acknowledgement. This work was sponsored by Supported by Foundation of Jiangxi Educational Committee(GJJ09210). 


\section{References}

1. Li, H.: Hydraulic control system. National Defence Industry Press, Beijing (February 1981)

2. Wang, C.: Hydraulic servo control system. China Machine Press, Beijing (1993)

3. Eryilmaz, B., Wilson, B.H.: Unified Modeling and Analysis of a Proportional Valve. Journal of the Franklin Institteu 343(1), 48-68 (2006)

4. Liu, J.-R., Jin, B., Xie, Y.-J., Chen, Y., Weng, Z.-T.: Research on the electro- hydraulic variable valve actuation system based on a three-way proportional reducing Automovalve. International Journal of tive Technology 10(1), 27-36 (2009)

5. Guan, J.T.: Electro hydraulic Control Technique. Tongji University Press, Shanghai (2003)

6. Wang, C.: Electro-Hydraulic Servo Control System. China Machine Press, Beijing 